\title{
Influence of Flax Fibre Hybridization on Mechanical Behaviour of Sisal Fibre-Polypropylene Composites Prepared with an Injection Moulding Machine
}

\author{
J. Allen Jeffrey, ${ }^{1}$ A. Sivakumar, ${ }^{1}$ R. Naveen Kumar, ${ }^{1}$ A. Anbazhagan, ${ }^{1}$ G. Manojkumar, \\ Sami Al Obaid, ${ }^{3}$ Saleh Alfarraj, ${ }^{4}$ S. Sivakumar, ${ }^{5}$ and S. Rajkumar ${ }^{6}{ }^{6}$ \\ ${ }^{1}$ Department of Mechanical Engineering, Loyola Institute of Technology, Chennai 600 123, Tamil Nadu, India \\ ${ }^{2}$ Department of Mechanical Engineering, Arjun College of Technology, Coimbatore 642 120, Tamilnadu, India \\ ${ }^{3}$ Department of Botany and Microbiology, College of Science, King Saud University, PO Box 2455, Riyadh -11451, Saudi Arabia \\ ${ }^{4}$ Zoology Department, College of Science, King Saud University, Riyadh 11451, Saudi Arabia \\ ${ }^{5}$ Department of Bioenvironmental Energy, College of Natural Resources \& Life Science, Pusan National University, \\ Miryang-si-50463, Republic of Korea \\ ${ }^{6}$ Department of Mechanical Engineering, Faculty of Manufacturing, Institute of Technology, Hawassa University, Ethiopia
}

Correspondence should be addressed to S. Rajkumar; rajkumar@hu.edu.et

Received 25 August 2021; Accepted 22 October 2021; Published 22 November 2021

Academic Editor: P Ganeshan

Copyright $\odot 2021$ J. Allen Jeffrey et al. This is an open access article distributed under the Creative Commons Attribution License, which permits unrestricted use, distribution, and reproduction in any medium, provided the original work is properly cited.

Due to their low weight, high specific strength, and low environmental impact, sisal fibre-polypropylene composites have gained popularity. However, the material has a low modulus and poor moisture resistance, among other shortcomings. This study investigated how flax fibre hybridization affects the physical parameters of sisal fibre-polypropylene composites. We used maleic anhydride-grafted polypropylene to improve compatibility between fibres and polypropylene. Adding flax fibres to polypropylene-silica composites resulted in increased tensile strength, flexibility, and impact strength, according to researchers. Water resistance was further improved by adding flax fibres. Tensile strength values of polypropylene-sisal fibre composites filled with 0 , $5,10,15$, and $20 \mathrm{wt} \%$ of flax fibres were $29.46,30.56,31.57,33.12$, and $34.64 \mathrm{MPa}$, respectively.

\section{Introduction}

In recent years, researchers have shifted their attention to developing pollution-free green composites that can replace polymer materials in commercial applications. In the development of natural composites, environmental resources have been used as reinforcement materials [1]. Organic fibre composite materials are used in the automobile and furniture industries. At present, coir, jute, and flax are the three most important organic fibres. They are also biodegradable [2]. Biodegradability and renewability of natural fibres make them effective reinforcement materials for composites [3]. Due to the availability of biocomposites, their use has skyrocketed across a variety of industries. Due to the scarcity of synthetic and traditional materials, most material science research focuses on biomaterials. Biocomposites have been studied by a number of academicians. These particles show superior hardness when mixed with epoxy resin matrix and banana fibre composites [4]. Due to their reduced compatibility with hydrophobic polymer matrixes, hydrophilicity is a disadvantage for natural fibres [5-9]. In composites with lignocellulosic fibres and polymeric matrix, such as polypropylene (PP), low levels of dispersion and adhesion occur [10]. Using acid compounds, organosilanes, or alkali treatments, fibre surfaces can be altered to adhere to each other. It has been demonstrated that the maleic anhydridepolypropylene copolymer is a very effective lignocellulosic fibre/PP composite compatibilizer [11-15]. In temperate and subtropical climates, flax fibres are formed in the inner bark of the stem. Flax fibre is a cellulosic, multicellular bast fibre 
composed of natural materials like wood and cellulose. Flax fibres range from 10 to 100 centimetres in length. They have a 35-90 $\mathrm{m}$ diameter range. Because their polymers are almost perpendicular to the fibre axis, flax is more durable than cotton. Flax is an ancient textile material. Linen is the fabric name given to flax, the plant that is used to produce it. Several studies have compared the mechanical properties of natural fibre/organic matrix composites after similar treatments [16-19]. Fibre-reinforced composites made of natural fibres have a lower modulus and strength than those made of glass fibres and are less resistant to moisture. Two or more fibre types in a single matrix can improve a composite's mechanical performance $[13,15,20]$. Hybrid composites provide a wide range of material properties in the end. As a result, one type of fibre can compensate for the shortcomings of the other [21-25]. Using a combination of glass and natural fibres, we create hybrid composites that offer superior mechanical performance and environmental benefits. An effective material design could achieve a balance between performance and environmental benefits [26]. As a coupling agent, the maleic anhydride-polypropylene copolymer improved the mechanical properties of flax fibre-PP composites [27]. A flax-sisal fibre/polypropylene composite was examined for its mechanical properties. The mechanical and water absorption properties of these composite materials were compared with those of flax fibre-added composites [28-30]. In addition to impact strength, we compared sisal/ flax blend strength, Young's modulus, flexural strength, and flexibility modulus. Flax fibre/polypropylene matrix composites and hybrid composites were also evaluated for their water absorption capacities. Figure 1 reveals the challenges and technical problems faced during fabrication of natural fibre composites.

\section{Experimental Arrangements}

2.1. Materials. Shine Polymers \& Trading provided polypropylene. Crystal Fiber Products supplied the sisal fibres. Bharatiya Natural Fibres provided flax fibres in roving shape. The sisal and flax fibres had densities of 1.39 and $2.41 \mathrm{~g} / \mathrm{cm}^{3}$, respectively. Super Chemical Traders supplied polypropylene grafted with maleic anhydride, which was used as a compatibilizer.

2.2. Sisal Fibres. 1.45 grams per cubic centimetre of real density and 1.20 grams per cubic centimetre of apparent density have been observed in this material. At 65\% relative humidity, moisture regain capacity is $11 \%$, while at $100 \%$ $\mathrm{RH}$, moisture regain capacity is $32 \%$. The fibre has a moderate crystalline structure. Around the fibre axis, the spiral angle is $20-25^{\circ} .9 .7 \%$ elastic strain is found in sisal fibres with a diameter of $21.5103 \mathrm{~cm}$. Transverse compression of these fibres is higher than longitudinal compression. Lignin in sisal fibres causes them to fade rapidly when exposed to sunlight. The moisture reabsorption value of these fibres is affected by their swelling. Despite their low porosity, plant fibres with high moisture absorption swelling do not show much change in porosity. This indicates a less organised molecular arrangement in indirectly dried fibres. The chemical, physical, and mechanical composition of sisal fibres is shown in Table 1.

2.3. Flax Fibres. They range from 25 to 150 "millimetres in length and have a diameter of 12 to 16 "micrometres. Shorter tow fibres are used for coarser fabrics, while longer line fibres are used for refined fabrics. The flexibility and texture of the fabric are enhanced by flax fibre's "nodes." Flax fibres have irregular polygonal cross sections, which contribute to the fabric's abrasive surface. The chemical composition of flax fibres is given in Table 2.

2.4. Preparation of Fibres. Sisal and flax fibres of five millimetres were cut. A total of three hours of cooking in a methanol/benzene mixture was required to remove waxes and low-molecular-weight species from the fibres before further processing. Hemicellulose was removed from the fibres by soaking them in a $3 \% \mathrm{NaOH}$ solution for three hours before washing. In the following days, we rinsed and dried the fibres at $90^{\circ} \mathrm{C}$ over the course of 24 hours.

2.5. Composite Preparation. In a vacuum oven set at $150^{\circ} \mathrm{C}$ for 14 hours, the fibres were dried before being mixed. Chemical treatments and compounding processes were used to determine the mechanical properties of flax and sisal fibre blends. Ingredients were mixed in an internal mixer and extruded using a twin screw extruder to create the final product. In the internal mixer, they were all mixed for 15 minutes at $60 \mathrm{rpm}$ and $190^{\circ} \mathrm{C}$ after they were loaded. A speed of $60 \mathrm{rpm}$ was set to run the twin screw extruder (rpm). The first zone was set at $170^{\circ} \mathrm{C}$, the second at $180^{\circ} \mathrm{C}$, the third at $185^{\circ} \mathrm{C}$, and the fourth at $190^{\circ} \mathrm{C}$ (at die). Figure 2 depicts the twin screw extrusion process in schematic form.

A 12 -hour vacuum oven at $120^{\circ} \mathrm{C}$ was used for both mixing procedures. Using an injection moulding machine, the pellets were injected in dry form. Plastic pellets were injected directly into the injection moulding machine as a comparison. As shown in Figure 3, the injection moulding process follows a flow chart. The ASTM D5943, ASTM D638, ASTM D256, and ASTM D570 standards were followed in the moulding of the samples. The true fibre content of composites was determined using xylene. In an oven, the recovered fibres were dried and weighed after the matrix had been dissolved and removed. Table 3 shows the different composite compositions and their descriptions.

\subsection{Characterizations}

2.6.1. Measurement of Fibre Length. The composites were heated in a furnace for 4 hours at $500^{\circ} \mathrm{C}$ to eliminate short glass fibres. The length of the fibres was determined using a reflectance light microscope on 200 samples.

2.6.2. Evaluation of Mechanical Properties. The speed of the Universal Testing Machine was set at five millimetres per second during the testing. ASTM D256-compliant impact 


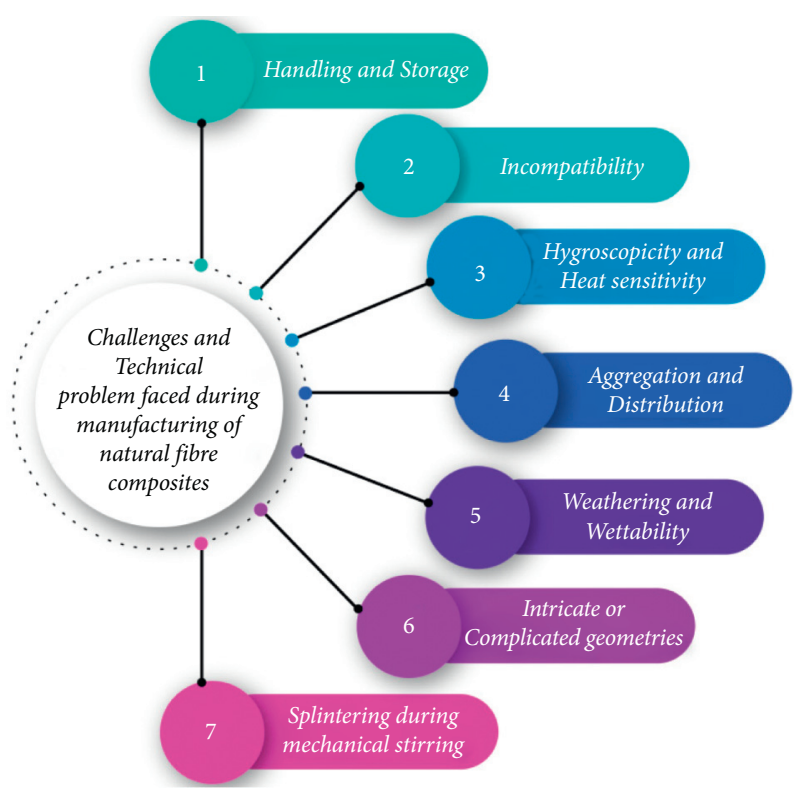

FIgURE 1: Challenges and technical problems faced during fabrication of natural fibre composites.

TABLe 1: Chemical, physical, and mechanical composition of sisal fibres.

\begin{tabular}{lc}
\hline Ingredients & Sisal fibres $(\%)$ \\
\hline Cellulose & $41.6-62.6$ \\
Hemicellulose & $9.2-14.6$ \\
Lignin & $11.4-19.5$ \\
Density $\left(\mathrm{g} / \mathrm{cm}^{3}\right)$ & $1.28-1.42$ \\
Tensile strength $(\mathrm{MPa})$ & $126-860$ \\
Tensile modulus $(\mathrm{GPa})$ & $4.6-16.8$ \\
Elongation $(\%)$ & $1.54-3.85$ \\
Fibre diameter $(\mu \mathrm{m})$ & $145-440$ \\
\hline
\end{tabular}

TABLE 2: Chemical composition of flax fibres.

\begin{tabular}{lcc}
\hline Ingredients & Raw flax\% & Retted flax\% \\
\hline Cellulose & 56.5 & 64.1 \\
Hemicellulose & 15.4 & 16.7 \\
Pectin & 3.8 & 1.8 \\
Lignin & 2.5 & 2.0 \\
Fat and wax & 1.3 & 1.5 \\
Water solubility & 10.5 & 3.9 \\
Moisture regain capacity (water) & 10.0 & 10.0 \\
Total & $100 \%$ & $100 \%$ \\
\hline
\end{tabular}

tests were performed on Izods that had been notched. A hammer used to test the composite's impact characteristics weighed $25 \mathrm{~kg}$. The crosshead speed on an ASTM D5943compliant Universal Testing Machine was $5 \mathrm{~mm} / \mathrm{s}$. Figure 4 reveals the impact test specimen position.

2.7. Water Absorption Properties. According to ASTM D570, PP and fibre composites were tested for water absorption. During this experiment, five samples were submerged in distilled water ( 2 days). The water absorption rate formula is given as follows: percentage of water absorption $=\frac{(S W 2-S W 1)}{S W 1} \times 100$,

where $\mathrm{SW}_{1}=$ specimen weight before the test (grams) and $\mathrm{SW}_{2}=$ specimen weight after the test (grams).

\section{Results and Discussion}

\subsection{Mechanical Properties}

3.1.1. Ultimate Tensile Strength and Young's Modulus. Composite materials, as shown in Figure 5, have high tensile strength and yield stress. When sisal fibres were added to polypropylene, Young's modulus increased. After flax fibres had been added to polypropylene/sisal fibre composites, tensile strength as well as Young's modulus increased. The interfacial adhesion of sisal-flax fibres and polypropylene matrix increased as a result of the composites' improved tensile properties. In comparison with polypropylene-sisal fibre composites, flax fibre-reinforced composites with a final tensile strength of $34.64 \mathrm{MPa}$ have the best bonding and load-carrying capacity. Moreover, 0 wt $\%$ flax fibre-reinforced composites have a minimum tensile strength of 29.46 MPa. Tensile strength values of polypropylene-sisal fibre composites filled with $0,5,10,15$, and $20 \mathrm{wt} \%$ of flax fibres were 29.46, 30.56, 31.57, 33.12, and $34.64 \mathrm{MPa}$, respectively. Figure 6 illustrates how flax fibre content affects Young's modulus in pure and hybrid composites.

Using sisal fibre and polypropylene as a base, composites with a glass fibre content of $30 \mathrm{wt} \%$ were investigated to test the effects of glass fibre on composites. The 22.84 vol percent for sisal fibre and 14.23 vol percent for glass fibre are used to fabricate the composites. Adding glass fibres to the sisal fibre-polypropylene composite increased its strength slightly. Flax fibres, on the other hand, had no effect on Young's modulus and flexural modulus of polypropylene-silica fibre composites. Young's modulus and flexural modulus of polypropylene-sisal fibre composites were not significantly different when flax fibres were added. Flax fibre contents of $0,5,10,15$, and $20 \mathrm{wt} \%$ correspond to $3.89,5.42,6.44,9.97$, and $10.62 \mathrm{vol} \%$, respectively. Sisal fibre-polypropylene composites were found to have little or no synergistic effect when flax fibres were added, according to the study.

3.1.2. Flexural Strength and Flexural Modulus. Bending the composite specimens in three directions results in a high degree of flexibility (see Figure 7). Due to the highest possible amount of flax fibre content present inside the composites, composite specimens reinforced with $20 \mathrm{wt} \%$ flax fibre had a better flexural strength of $71.38 \mathrm{MPa}$. The entire absence of flax fibre particles inside the composite specimens resulted in a minimum flexural strength of $67.01 \mathrm{MPa}$, that is, in $0 \mathrm{wt} \%$ flax fibre-polypropylene composites. The flexural strength ranged from $66.51 \mathrm{MPa}$ to $71.38 \mathrm{MPa}$ when polypropylene matrix-sisal fibre-reinforced composites were mixed with flax fibres at $0,5,10,15$, and 20 wt $\%$. It was found that increasing the flax fibre content had 


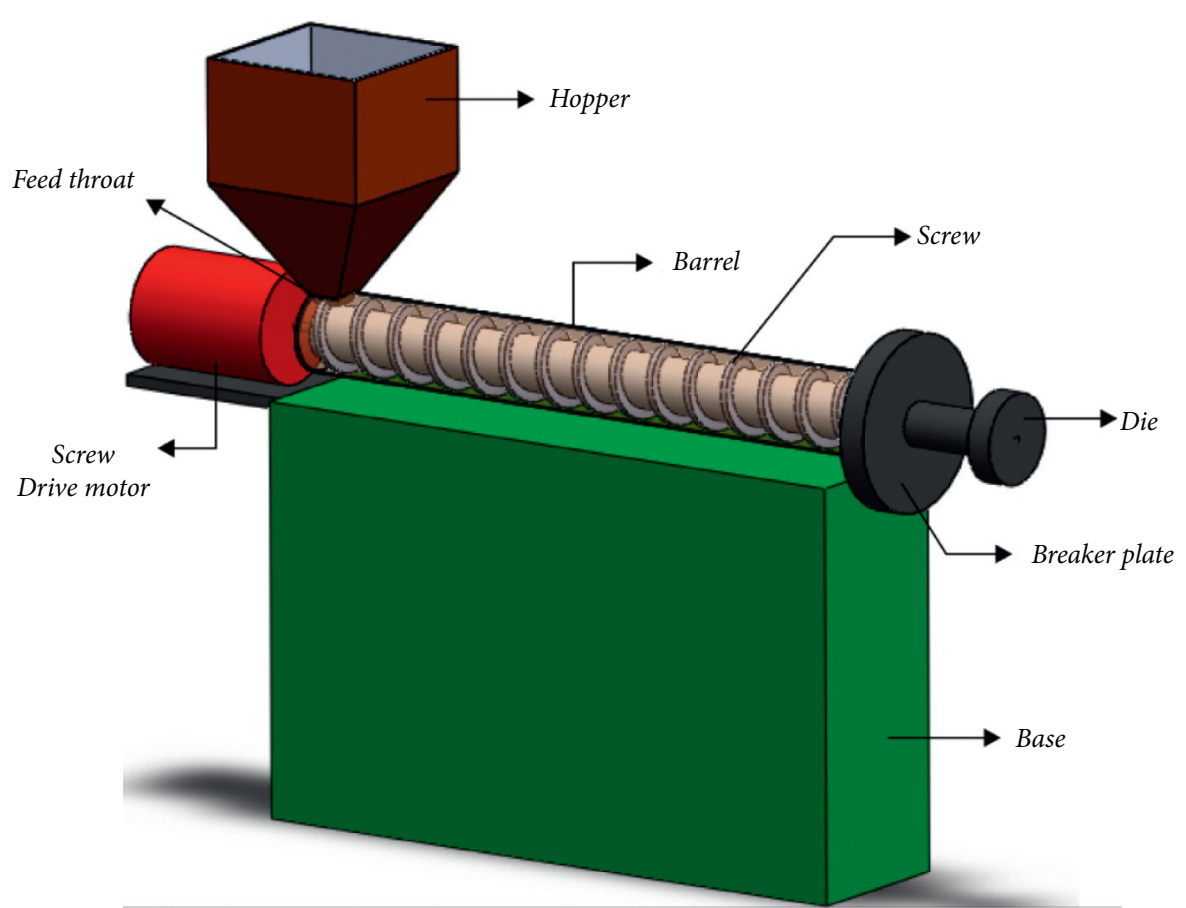

FIGURE 2: Schematic of the twin screw extrusion process.

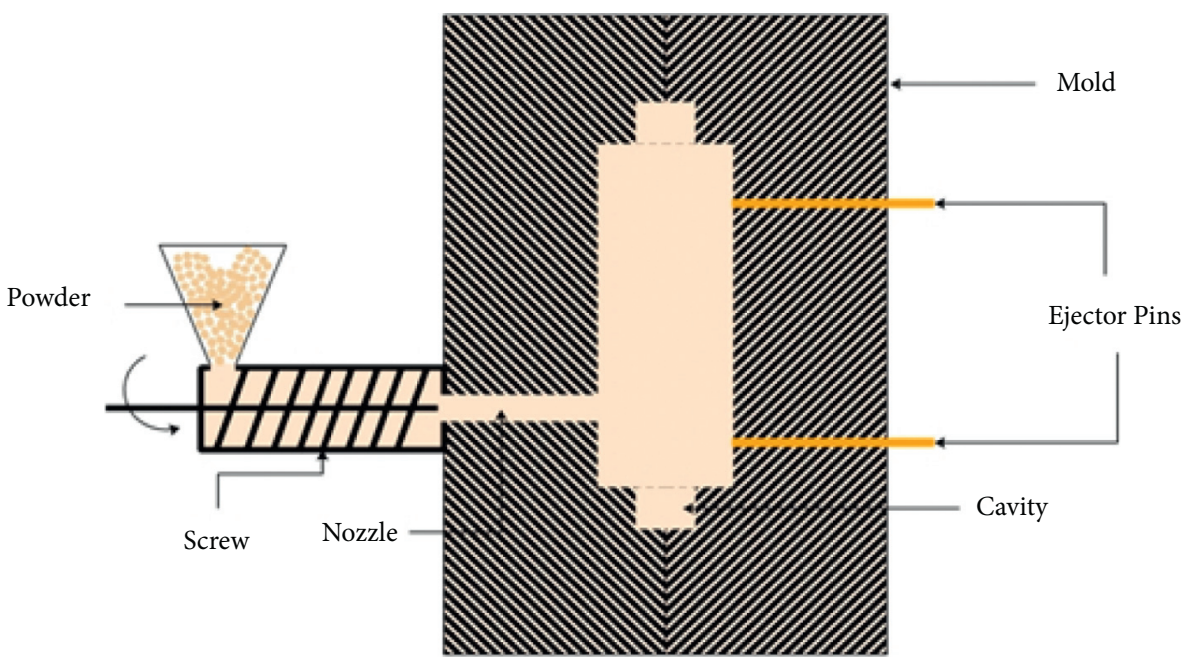

FIgURE 3: Schematic of the injection moulding process.

TABLe 3: Detailed description of the composite specimens and its compositions.

\begin{tabular}{lccc}
\hline Description of the composite specimen & Polypropylene (PP) (wt\%) & Sisal fibres (wt\%) & Flax fibres (wt\%) \\
\hline PP & 100 & 0 & 0 \\
PP/SF & 70 & 30 & 0 \\
PP/FF & 70 & 0 & 30 \\
PP/25SF/5FF & 70 & 25 & 05 \\
PP/20SF/10FF & 70 & 20 & 10 \\
PP/15SF/15FF & 70 & 15 & 15 \\
PP/10SF/20FF & 70 & 10 & 20 \\
\hline
\end{tabular}

no significant impact on hybrid composites' flexural properties during the mixing process and the flax fibres were thoroughly mixed, as shown in Figure 8.
Flexural moduli of pure and hybrid composites were affected by flax fibre content, as shown in Figure 8 . In polypropylene-sisal fibre composites reinforced with $0 \mathrm{wt} \%$ 


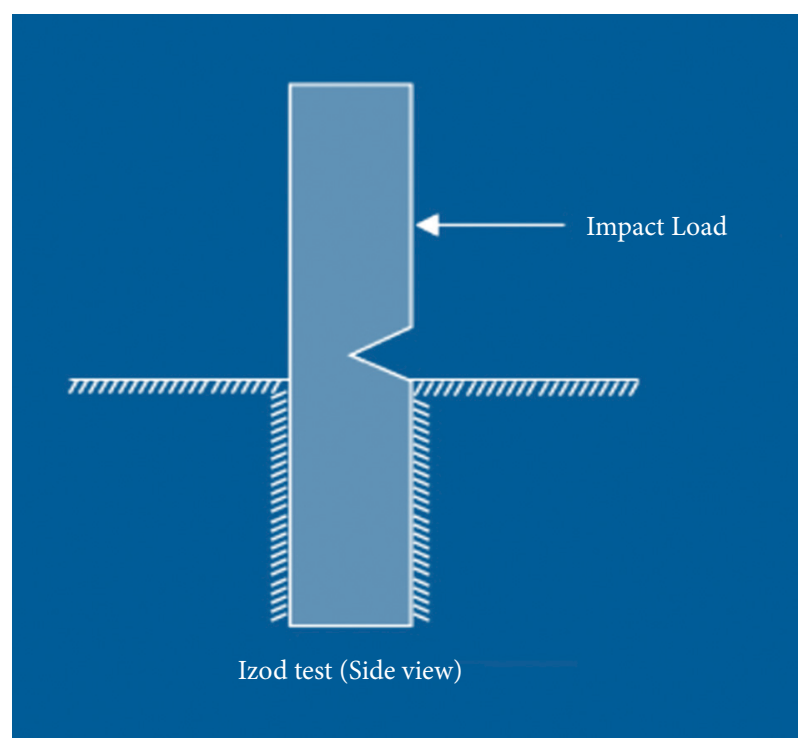

FIgURE 4: Impact test specimen position.

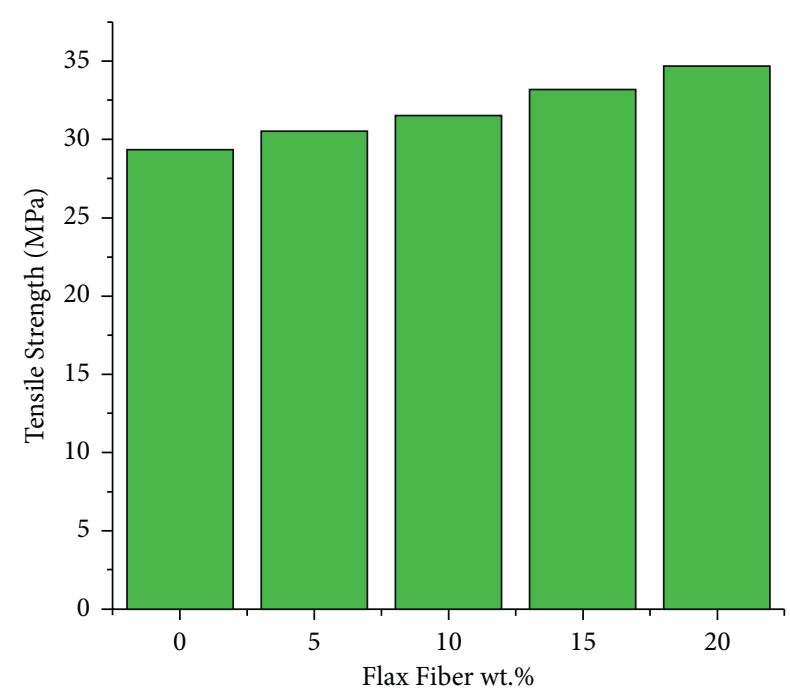

Figure 5: Effect of flax fibre content on tensile strength of pure and hybrid composites.

and 20 wt $\%$ of flax fibres, the maximum and minimum three-point bending test moduli were found to be 1.32 and $4.82 \mathrm{GPa}$, respectively. Composites reinforced with five, ten, fifteen, and twenty wt\%. of fibres had flexural modulus values of $1.89,3.97,4.36$, and $4.38 \mathrm{GPa}$, respectively. Flax fibres were added to epoxy polypropylene matrix-sisal fibrereinforced composites to improve the flexural modulus.

3.1.3. Impact Strength. Adding flax fibres to natural fibrepolypropylene composites, on the other hand, was found to improve mechanical performance as per a number of researchers. Polypropylene's impact strength as a stress concentrator was lowered when sisal fibres were added. Impact strength of sisal-polypropylene composites was improved by adding flax fibres. The impact strength of composite specimens during the Izod impact test is shown in Figure 9. Flax

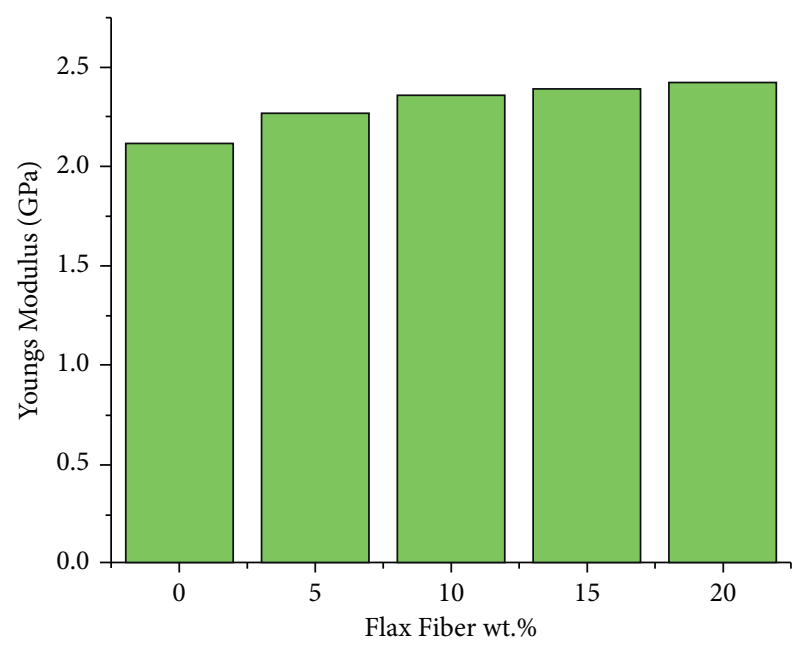

Figure 6: Effect of flax fibre content on Young's modulus of pure and hybrid composites.

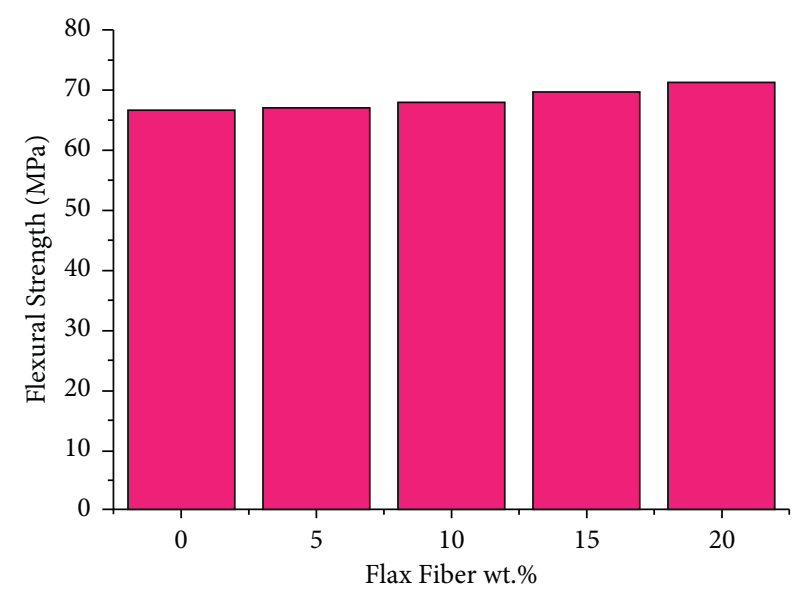

Figure 7: Effect of flax fibre content on flexural strength of pure and hybrid composites.

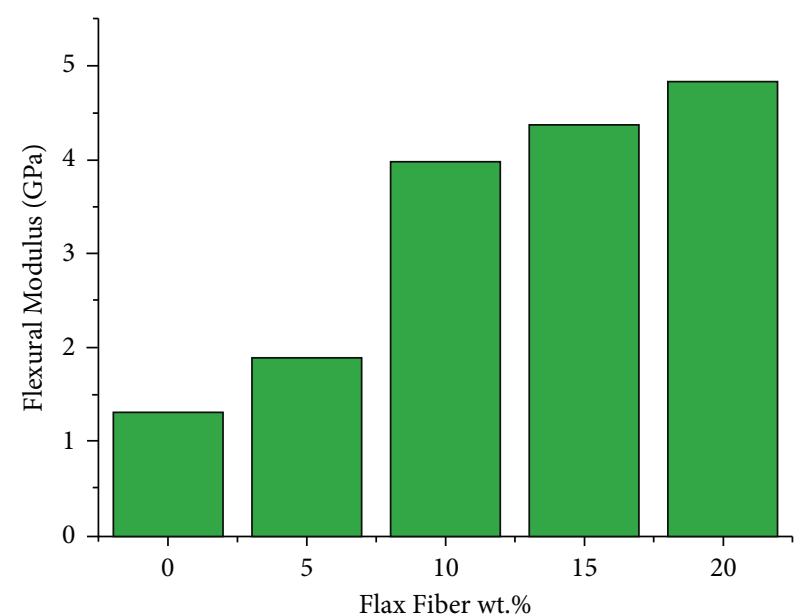

FIgURE 8: Effect of flax fibre content on flexural modulus of pure and hybrid composites. 


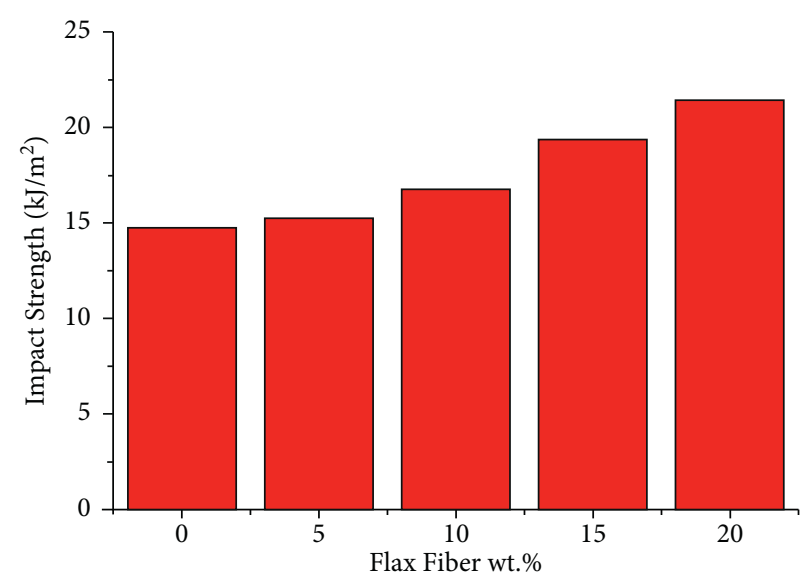

FIGURE 9: Effect of flax fibre content on impact strength of pure and hybrid composites.

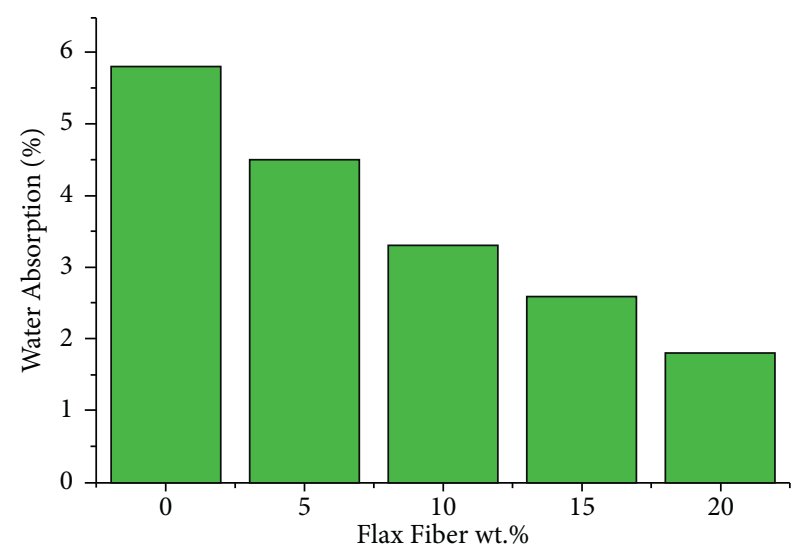

FIGURE 10: Water absorption of pure and hybrid composites during 48 hours of immersion in water.

fibre composites containing $0,5,10,15$, and $20 \%$ flax fibres had impact strengths of $14.78,15.23,16.86,19.48$, and $21.52 \mathrm{~kJ} / \mathrm{m}^{2}$. Surprisingly, as the weight percentage of flax fibres dispersed in the polypropylene-sisal fibre-reinforced composites increased, the specimens' impact strength improved. The highest impact strength of the $20 \mathrm{w} \%$ flax fibrereinforced composites was $21.52 \mathrm{~kJ} / \mathrm{m}^{2}$, while the minimum impact strength of the $0 \mathrm{wt} \%$ flax fibre-reinforced composites was $14.78 \mathrm{~kJ} / \mathrm{m}^{2}$.

3.1.4. Water Absorption Behaviour. The water absorption behaviour of sisal-flax fibre-polypropylene composite is shown in Figure 10. Water absorption in sisal fibre-polypropylene composites was found to be reduced by flax fibres. In a polypropylene matrix containing flax and sisal fibres, researchers found that water absorption decreased.

\section{Conclusions}

A polypropylene matrix reinforced with sisal fibres was subjected to a flax fibre addition experiment to determine the mechanical properties of the composite. In addition to improving composite tensile, flexural, and impact properties, the compatibilizer improved interfacial adhesion. It was found that the fusion of flax fibres did not significantly improve the mechanical properties of composite materials. When compared to other weight percentages of flax fibres, composites comprising $20 \mathrm{wt} \%$ flax fibres, which were added into the polypropylene matrix-sisal fibre-reinforced biocomposites, demonstrated superior tensile and flexural behaviour. The water absorption of sisal-PP composites was reduced when they were hybridised with flax fibres. Flax fibre composites of $0,5,10,15$, and $20 \mathrm{wt} \%$ showed impact strengths of $14.78,15.23,16.86,19.48$, and $21.52 \mathrm{~kJ} / \mathrm{m}^{2}$.

\section{Data Availability}

The data used to support the findings of this study are included within the article. Further dataset or information is available from the corresponding author upon request.

\section{Conflicts of Interest}

The authors declare that there are no conflicts of interest regarding the publication of this article.

\section{Acknowledgments}

The authors appreciate the supports from Hawassa University, Ethiopia. The authors thank the Loyola Institute of Technology, Chennai, and Arjun College of Technology, Coimbatore, and this project was supported by researchers supporting project number (RSP-2021/315), King Saud University, Riyadh, Saudi Arabia.

\section{References}

[1] B. V. R. Girimurugan, N. Senniangiri, and K. Adithya, "Mechanical behaviour of coconut shell powder granule reinforced epoxy resin matrix bio composites," J. Adv. Res. Dyn. Control Syst.vol. 10, no. 12, pp. 531-544, 2018.

[2] R. G. C. Thiruvasagam, M. Selvaraj, S. Saravanan, and M. Vairavel, "Art of review - fiber reinforced polymer composites," Journal of Information and Computing Science, vol. 9, no. 11, pp. 461-468, 2019.

[3] G. Cantero, A. Arbelaiz, R. Llano-Ponte, and I. Mondragon, "Effects of fibre treatment on wettability and mechanical behaviour of flax/polypropylene composites," Composites Science and Technology, vol. 63, no. 9, pp. 1247-1254, 2003.

[4] R. Girimurugan, R. Pugazhenthi, P. Maheskumar, T. Suresh, and M. Vairavel, "Impact and hardness behaviour of epoxy resin matrix composites reinforced with banana fiber/camellia sinensis particles," Materials Today: Proceedings, vol. 39, pp. 373-377, 2021.

[5] P. Wambua, J. Ivens, and I. Verpoest, "Natural fibres: can they replace glass in fibre reinforced plastics?" Composites Science and Technology, vol. 63, no. 9, pp. 1259-1264, 2003.

[6] R. Gauthier, C. Joly, A. C. Coupas, H. Gauthier, and M. Escoubes, "Interfaces in polyolefin/cellulosic fiber composites: chemical coupling, morphology, correlation with adhesion and aging in moisture," Polymer Composites, vol. 19, no. 3, pp. 287-300, 1998. 
[7] J. C. M. De Bruijn, "Natural fibre mat thermoplastic products from a processor's point of view," Applied Composite Materials, vol. 7, no. 5, pp. 415-420, 2000.

[8] W. D. Brouwer, "Natural fibre composites: where can flax compete with glass?" SAMPE Journal, vol. 36, no. 6, pp. 18-23, 2000.

[9] A. K. Mohanty, M. Misra, and G. Hinrichsen, "Biofibres, biodegradable polymers and biocomposites: an overview," Macromolecular Materials and Engineering, vol. 276-277, no. 1, pp. 1-24, 2000.

[10] M. C. Matias, M. U. De La Orden, C. G. Sánchez, and J. M. Urreaga, "Comparative spectroscopic study of the modification of cellulosic materials with different coupling agents," Journal of Applied Polymer Science, vol. 75, no. 2, pp. 256-266, 2000.

[11] N. E. Zafeiropoulos, D. R. Williams, C. A. Baillie, and F. L. Matthews, "Engineering and characterisation of the interface in flax fibre/polypropylene composite materials. Part I. Development and investigation of surface treatments," Composites Part A: Applied Science and Manufacturing, vol. 33, no. 8, pp. 1083-1093, 2002.

[12] N. E. Marcovich, M. a. M. Reboredo, and M. I. Aranguren, "Dependence of the mechanical properties of woodflourpolymer composites on the moisture content," Journal of Applied Polymer Science, vol. 68, no. 13, pp. 2069-2076, 1998.

[13] L. Y. Mwaikambo, E. Martuscelli, and M. Avella, "Kapok/ cotton fabric-polypropylene composites," Polymer Testing, vol. 19, no. 8, pp. 905-918, 2000.

[14] M. Kazayawoko, J. J. Balatinecz, and R. T. Woodhams, "Diffuse reflectance Fourier transform infrared spectra of wood fibers treated with maleated polypropylenes," Journal of Applied Polymer Science, vol. 66, no. 6, pp. 1163-1173, 1997.

[15] K. Joseph, S. Thomas, and C. Pavithran, "Effect of chemical treatment on the tensile properties of short sisal fibre-reinforced polyethylene composites," Polymer, vol. 37, no. 23, pp. 5139-5149, 1996.

[16] R. Karnani, M. Krishnan, and R. Narayan, "Biofiber-reinforced polypropylene composites," Polymer Engineering \& Science, vol. 37, no. 2, pp. 476-483, 1997.

[17] P. R. Hornsby, E. Hinrichsen, and K. Tarverdi, "Preparation and properties of polypropylene composites reinforced with wheat and flax straw fibres," Journal of Materials Science, vol. 32, no. 4, pp. 1009-1015, 1997.

[18] B. V. Kokta, R. G. Raj, and C. Daneault, "Use of wood flour as filler in polypropylene: studies on mechanical properties," Polymer - Plastics Technology and Engineering, vol. 28, no. 3, pp. 247-259, 1989.

[19] F. M. B. Coutinho, T. H. S. Costa, and D. L. Carvalho, "Polypropylene-wood fiber composites: effect of treatment and mixing conditions on mechanical properties," Journal of Applied Polymer Science, vol. 65, no. 6, pp. 1227-1235, 1997.

[20] T. H. D. Sydenstricker, S. Mochnaz, and S. C. Amico, "Pullout and other evaluations in sisal-reinforced polyester biocomposites," Polymer Testing, vol. 22, no. 4, pp. 375-380, 2003.

[21] J. George, M. S. Sreekala, and S. Thomas, "A review on interface modification and characterization of natural fiber reinforced plastic composites," Polymer Engineering \& Science, vol. 41, no. 9, pp. 1471-1485, 2001.

[22] A. C. Karmaker and J. A. Youngquist, "Injection molding of polypropylene reinforced with short jute fibers," Journal of Applied Polymer Science, vol. 62, no. 8, pp. 1147-1151, 1996.

[23] K. Oksman and C. Clemons, "Mechanical properties and morphology of impact modified polypropylene-wood flour composites," Journal of Applied Polymer Science, vol. 67, no. 9, pp. 1503-1513, 1998.

[24] J. M. Felix and P. Gatenholm, "The nature of adhesion in composites of modified cellulose fibers and polypropylene," Journal of Applied Polymer Science, vol. 42, no. 3, pp. 609-620, 1991.

[25] A. K. Rana, A. Mandal, B. C. Mitra, R. Jacobson, R. Rowell, and A. N. Banerjee, "Short jute fiber-reinforced polypropylene composites: effect of compatibilizer," Journal of Applied Polymer Science, vol. 69, no. 2, pp. 329-338, 1998.

[26] C. Chuai, K. Almdal, L. Poulsen, and D. Plackett, "Conifer fibers as reinforcing materials for polypropylene-based composites," Journal of Applied Polymer Science, vol. 80, no. 14 , pp. 2833-2841, 2001.

[27] M. M. Thwe and K. Liao, "Durability of bamboo-glass fiber reinforced polymer matrix hybrid composites," Composites Science and Technology, vol. 63, no. 3-4, pp. 375-387, 2003.

[28] V. Mohanavel, S. Suresh Kumar, J. Vairamuthu, P. Ganeshan, and B. NagarajaGanesh, "Influence of stacking sequence and fiber content on the mechanical properties of natural and synthetic fibers reinforced penta-layered hybrid composites," Journal of Natural Fibers, vol. 2021, Article ID 1875368, 13 pages, 2021.

[29] Y. Li, Y.-W. Mai, and L. Ye, "Sisal fibre and its composites: a review of recent developments," Composites Science and Technology, vol. 60, no. 11, pp. 2037-2055, 2000.

[30] A. Arbelaiz, B. Fernández, J. A. Ramos, A. Retegi, R. LlanoPonte, and I. Mondragon, "Mechanical properties of short flax fibre bundle/polypropylene composites: influence of matrix/ fibre modification, fibre content, water uptake and recycling," Composites Science and Technology, vol. 65, no. 10, pp. 1582-1592, 2005. 